\title{
Preparation and Characterization of Modified Polyethyleneimine Magnetic Nanoparticles for Cancer Drug Delivery
}

\author{
Sedighe Arabi, ${ }^{1}$ Hamid Akbari Javar, ${ }^{2}$ and Mehdi Khoobi ${ }^{3,4}$ \\ ${ }^{1}$ Department of Chemistry, Faculty of Sciences, Islamic Azad University, Arak Branch, Arak, Iran \\ ${ }^{2}$ Department of Pharmaceutics, Faculty of Pharmacy, Tehran University of Medical Sciences, Tehran 14176, Iran \\ ${ }^{3}$ Department of Pharmaceutical Biomaterials and Medical Biomaterials Research Center, Faculty of Pharmacy, \\ Tehran University of Medical Sciences, Tehran 14176, Iran \\ ${ }^{4}$ Department of Medicinal Chemistry, Faculty of Pharmacy and Pharmaceutical Sciences Research Center, \\ Tehran University of Medical Sciences, Tehran 14176, Iran \\ Correspondence should be addressed to Sedighe Arabi; arabi.sedighe58@gmail.com
}

Received 21 January 2016; Accepted 10 April 2016

Academic Editor: Zhiguang Wang

Copyright @ 2016 Sedighe Arabi et al. This is an open access article distributed under the Creative Commons Attribution License, which permits unrestricted use, distribution, and reproduction in any medium, provided the original work is properly cited.

\begin{abstract}
Magnetic nanoparticles with polymeric coating have great significance in drug delivery purpose. We intended to prepare a modified amphiphilic polymer with targeting susceptibility to reduce side effects to normal cells. In this study polyethyleneimine (PEI) as a polycationic polymer reacted with sebacoyl chloride to make a new amphiphilic polymer and folic acid as a targeting agent to reduce cytotoxicity of polymer and increase specific entrance of nanoparticles to cancerous cells. The obtained polymer (PEI-Sb-FA) was then coated on magnetic nanoparticles (MNPs) to stabilize them. The core-shell nanoparticles were characterized by different methods such as scanning electron microscopy (SEM), X-ray diffraction (XRD), thermogravimetric analysis (TGA), and vibrating sample magnetometer (VSM). Curcumin was finally loaded on PEI-Sb-FA-MNPs and the release behavior was studied in different $\mathrm{pH}$. Curcumin loading of $28.2 \%$ was obtained and released drug in acidic $\mathrm{pH}=4.5$ was more than $\mathrm{pH}=7.4$, showing drug release sensitivity toward $\mathrm{pH}$ of media.
\end{abstract}

\section{Introduction}

Efficiency of many existing drugs is restricted by their poor solubility in water and toxicity against normal cells [1]. Traditional chemotherapy is not commonly successful in cancer therapy due to the severe side effects of anticancer drugs and induced toxicity. However nanotechnology can reduce these side effects including dermatologic, cardiac, gastrointestinal, nervous system-related, and hematologic effects. In drug delivery, it is important to deliver a medicine to the target site of therapeutic action with a specific dose [2]. For this purpose different carriers have been designed such as liposomes, hydrogels, biodegradable polymers, and magnetic nanoparticles. Polymeric nanoparticles have been widely used in drug delivery because they have small sizes that enable them to be transferred into the body from different routes [3].
The concept of drug delivery by magnetic nanoparticles was proposed by Widder et al. in 1978 [4]. They coated magnetic nanoparticles with polymeric shell as suitable carriers for drug delivery due to their high stability and super paramagnetism behavior and more biocompatibility. Polymers have emerged as an efficient biocompatible coating agent with the ability of tuning the surface functionality. Yallapu et al. [5] introduced magnetic drug carriers with a pluronic polymer (F127) shell for controlled delivery of curcumin. Iron oxide is one of the nanoparticles that is used for magnetic resonance imaging and cancer treating. The polymeric nanoparticles can be prepared via two different strategies including (a) $\mathrm{Fe}_{3} \mathrm{O}_{4}$ nanoparticles coating with a layer of polymer and (b) $\mathrm{Fe}_{3} \mathrm{O}_{4}$ nanoparticles precipitated in the presence of a porous polymer [6]. Polyethyleneimine (PEI) is a synthetic polymer that is frequently used in gene delivery systems. Amine 
groups can be functionalized through different methods to control its toxicity [7].

For decades there has been rapid increase in using natural products for cancer therapy. One of these natural products is curcumin. Curcumin is extracted from Curcuma longa, possessing a number of beneficial biological characteristics [8].

In this work, $\mathrm{Fe}_{3} \mathrm{O}_{4}$ magnetic nanoparticles coated with a $\mathrm{pH}$ sensitive polymer and folic acid were used to increase targeting. The solubility of curcumin was increased by inclusion in the iron nanoparticles coated with modified polymer.

\section{Materials and Methods}

2.1. Materials. PEI $(\mathrm{MW}=60000)$, sebacoyl chloride, acetone, folic acid, dimethyl sulfoxide (DMSO), ethanol, sorbitan monooleate (Span 80), triethylamine, ninhydrin, cyclohexane, N-hydroxysuccinimide, methanol, iron (III) chloride hexahydrate $\left(\mathrm{FeCl}_{3}, 6 \mathrm{H}_{2} \mathrm{O}\right)$, iron (II) chloride tetrahydrate $\left(\mathrm{FeCl}_{2}, 4 \mathrm{H}_{2} \mathrm{O}\right)$, disodium hydrogen phosphate, curcumin, $\left(\mathrm{Na}_{2} \mathrm{HPO}_{4}, 12 \mathrm{H}_{2} \mathrm{O}\right)$, potassium dihydrogen phosphate $\left(\mathrm{KH}_{2} \mathrm{PO}_{4}\right)$, potassium iodate $\left(\mathrm{KIO}_{3}\right)$, and acetonitrile were used. All of the reagents were analytical grade, purchased from Sigma Aldrich and used as soon as received without further purification. Deionized water was used to prepare all aqueous solutions.

2.2. Synthesis of $\mathrm{Fe}_{3} \mathrm{O}_{4}$ Nanoparticles. The coprecipitation method was used for the preparing of $\mathrm{Fe}_{3} \mathrm{O}_{4}$ nanoparticles. This method applies ferric and ferrous ions in a 1:2 molar ratio [9]. According to the procedure, $3.17 \mathrm{~g}$ of $\mathrm{FeCl}_{2} \cdot 4 \mathrm{H}_{2} \mathrm{O}$ $(0.016 \mathrm{~mol})$ and $7.68 \mathrm{~g}$ of $\mathrm{FeCl}_{3} \cdot 6 \mathrm{H}_{2} \mathrm{O}(0.008)$ were dissolved in $50 \mathrm{~mL}$ of deionized water. The mixture was stirred under $\mathrm{N}_{2}$ at $85^{\circ} \mathrm{C}$ for $1 \mathrm{hr}$. Then $40 \mathrm{~mL}$ of $\mathrm{NH}_{4} \mathrm{OH}$ solution was added and stirred under $\mathrm{N}_{2}$ for $1 \mathrm{hr}$ and then cooled to room temperature. The precipitated particles were washed three times with deionized water and were separated by a magnet and then dried under vacuum at $65^{\circ} \mathrm{C}$.

2.3. Synthesis of PEI-Sb. Modified branched PEI network was prepared via interfacial polycondensation reaction between PEI (MW $=60,000)$ and sebacoyl chloride. A $2 \% \mathrm{v} / \mathrm{v}$ solution of Span 80 in cyclohexane $(100 \mathrm{~mL})$ was mixed with $30 \mathrm{~mL}$ of $10 \%$ wt aqueous solution of PEI $(\mathrm{pH}=8.0)$. The mixture was stirred and $1.92 \mathrm{~g}(8 \mathrm{mmol})$ of sebacoyl chloride $(\mathrm{sb})$ in $4 \mathrm{~mL}$ of cyclohexane was added. The reaction was allowed to proceed for $15 \mathrm{~min}$ under argon in ice bath and then it was diluted with $100 \mathrm{~mL}$ of cyclohexane. The resultant product in the form of beads settled within 1 day and was then separated from the liquid and rinsed several times with $100 \mathrm{~mL}$ of cyclohexane. The beads were transferred into the aqueous phase by dispersing the product in $100 \mathrm{~mL}$ of polysorbate 20 (Tween 20$)(30 \% \mathrm{v} / \mathrm{v})$ and $500 \mathrm{~mL}$ of deionized water was gradually added. The beads were then filtered and rinsed with water to eliminate traces of impurities [10].

2.4. Ninhydrin Test. The content of primary amino groups in PEI-Sb was determined using ninhydrin colorimetry test [11]. Polyethyleneimine was used as standard to prepare the calibration curve $(40,55,120$, and $150 \mathrm{ppm})$. Absorbance measurements were determined at $570 \mathrm{~nm}$ wavelength. $2 \mathrm{~mL}$ of PEI in mentioned concentrations and PEI-seb solution $(150 \mathrm{mg} / \mathrm{mL})$ were prepared and then $1 \mathrm{~mL}$ of ninhydrin $(0.005 \mathrm{~g} / \mathrm{L})$ reagent was added to every solution. The samples were subsequently heated in a boiling water bath for exactly 15 minutes and cooled to $20^{\circ} \mathrm{C}$ for 20 minutes. Afterwards $5 \mathrm{~mL}$ of diluting solution was added and mixed and the absorbance was measured at $570 \mathrm{~nm}$ by a UV-Vis spectrophotometer.

\subsection{Preparing of Folate-Conjugated Polymer (Folate-PEI-Sb).} Folic acid was initially activated by NHS [12]. In summary, folic acid $(1 \mathrm{~g})$ was dissolved in anhydrous DMSO $(30 \mathrm{~mL})$ and then NHS $(0.9 \mathrm{~g})$ and DCC $(0.5 \mathrm{~g})$ were added to the solution and the reaction was completed overnight by stirring at room temperature and under argon. 1,3-Dicyclohexylurea (DCU) was removed by filtration. To $5 \mathrm{~mL}$ of polymer solution containing PEI-Sb $(0.4 \mathrm{~g})$, triethylamine $(0.05 \mathrm{~mL})$ and then the filtered activated folate solution $(3 \mathrm{~mL})$ was added. The reaction proceeded at room temperature for $10 \mathrm{~h}$ under argon. Subsequently, the obtained solution was centrifuged and then filtered. After purification and rinsing, the obtained polymer was freeze-dried. The conversion of $\mathrm{NH}_{2}$-PEI-Sb into folate-PEI-Sb was evaluated by dissolving the polymer in DMSO. The absorbance was measured at $363 \mathrm{~nm}$ by Cecil UV-Vis spectrophotometer to confirm the presence of folate in the sample [13].

2.6. Preparation of Core-Shell Magnetic Nanoparticles. To prepare core-shell FA-PEI-Sb-MNP, $5 \mathrm{~mL}$ MNP $(10 \mathrm{mg} / \mathrm{mL})$ was dispersed in water helping ultrasonication. Then, FAPEI-Sb solution in DMSO $(5.5 \mathrm{mg} / \mathrm{mL})$ was mixed with the MNP dispersion. The suspension was stirred for $12 \mathrm{~h}$ at room temperature [14]. MNPs covered by polymer were collected by a permanent magnet and washed three times by deionized water and dried under vacuum desiccator.

2.7. Characterization of Magnetic Nanoparticles. Fourier transform infrared (FTIR) spectroscopy, X-ray diffraction (XRD), and thermal gravimetric analysis (TGA) were taken to characterize the magnetic nanoparticles. The magnetic properties measurements were carried out by vibrating sample magnetometry (VSM) at room temperature. Fourier transform infrared spectra (FTIR) were recorded in Nicolet 870 by a $\mathrm{KBr}$ pellet. XRD spectra were taken by a Bruker axs D8 advance diffractometer utilizing the X-ray beam from $\mathrm{Cu} \mathrm{K} \alpha$ radiation. TGA results were obtained using L70/2003 thermal analyzer. The temperature range was raised up to $800^{\circ}$, at a ramp of $10^{\circ} \mathrm{C} / \mathrm{min}$ with argon as inert gas. The VSM was applied to measure the magnetic properties of nanoparticles.

2.8. Drug Loading. $10 \mathrm{mg}$ curcumin was dissolved in $1 \mathrm{~mL}$ acetonitrile and added dropwise to $10 \mathrm{~mL}$ of an aqueous dispersion of PEI-Sb-FA-MNPs (10 mg). Afterwards, the suspension was stirred overnight to allow penetration of curcumin into polymeric layer in core-shell nanoparticles at $12000 \mathrm{rpm}$. The obtained nanoparticles were washed three times in water to remove unloaded curcumin. The loaded 


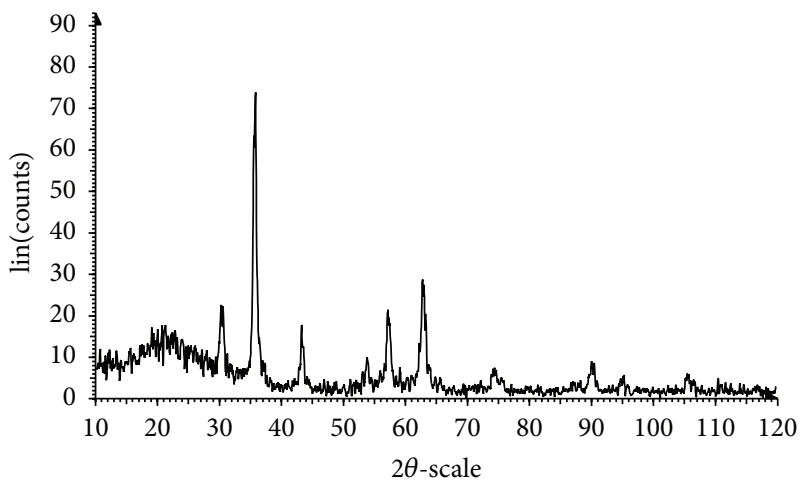

FIgURE 1: XRD of $\mathrm{Fe}_{3} \mathrm{O}_{4}$-Polymer.

curcumin was estimated at $450 \mathrm{~nm}$ wavelength by a UV-Vis spectrophotometer (Cecil 9000) [15].

2.9. In Vitro Release Experiments. Curcumin release from core-shell polymeric magnetic nanoparticles was accomplished in PBS at different $\mathrm{pH}$ levels ( $\mathrm{pH} 4.5$ and $\mathrm{pH}$ 7.4). Briefly, $10 \mu \mathrm{g}$ of MNPs containing curcumin was dispersed in $50 \mathrm{~mL}$ PBS solution in a tube. The sample was divided into centrifuged tubes and then placed in a shaking water bath with $120 \mathrm{rpm}$ at $37^{\circ} \mathrm{C}$. Because free curcumin is not soluble in water, the released curcumin in buffer at predetermined time intervals was centrifuged at $5000 \mathrm{rpm}$ for 15 minutes to remove the released curcumin and redissolved in $1 \mathrm{~mL}$ of DMSO and the absorbance of solutions was measured at $450 \mathrm{~nm}$ using a UV-Vis spectrophotometer. Concentration of the solutions was determined using a calibration curve obtained from curcumin solutions $(0-10 \mu \mathrm{g} / \mathrm{mL})[13,16]$.

\section{Results and Discussion}

The ninhydrin assay confirms that $54.63 \%$ of amine groups have been functionalized by carboxylic groups.

The XRD pattern shows magnetite peaks for iron oxide nanoparticles. The seven characteristic diffraction peaks $(20.1,30.1,35.6,43.1,53.8,57.2$, and 62.8) are indicating that the crystalline iron oxide was formed completely. The crystalline size was approximately $28 \mathrm{~nm}$ calculated by Scherrer's equation. Finally, the results indicate preservation of crystalline structure of $\mathrm{Fe}_{3} \mathrm{O}_{4}$ for the functionalized $\mathrm{Fe}_{3} \mathrm{O}_{4}$ NPs (Figure 1).

Thermal gravimetric analysis was performed to evaluate the thermal stability of the nanoparticles. This analysis was recorded from ambient temperature to $800^{\circ} \mathrm{C}$. Figure 2 shows the TGA curves for magnetic nanoparticles in nitrogen atmosphere at $20^{\circ} \mathrm{C} / \mathrm{min}$ ascending temperature. The weightloss areas were observed at $104.2^{\circ} \mathrm{C}, 232.2^{\circ} \mathrm{C}, 330.3^{\circ} \mathrm{C}$, and $451.5^{\circ} \mathrm{C}$, respectively. The first weight loss at the range of room temperature to $232^{\circ} \mathrm{C}$ could be attributed to the absorbed solvent evaporation. The second weight loss until around $451^{\circ} \mathrm{C}$ could be due to the polymer degradation on the surface of magnetic nanoparticles. Based on weight loss of about $10 \mathrm{mg}$ at the range of $232-451^{\circ} \mathrm{C}$, the coating amount of modified PEI on $\mathrm{Fe}_{3} \mathrm{O}_{4}$ was measured to be about $10 \%$.

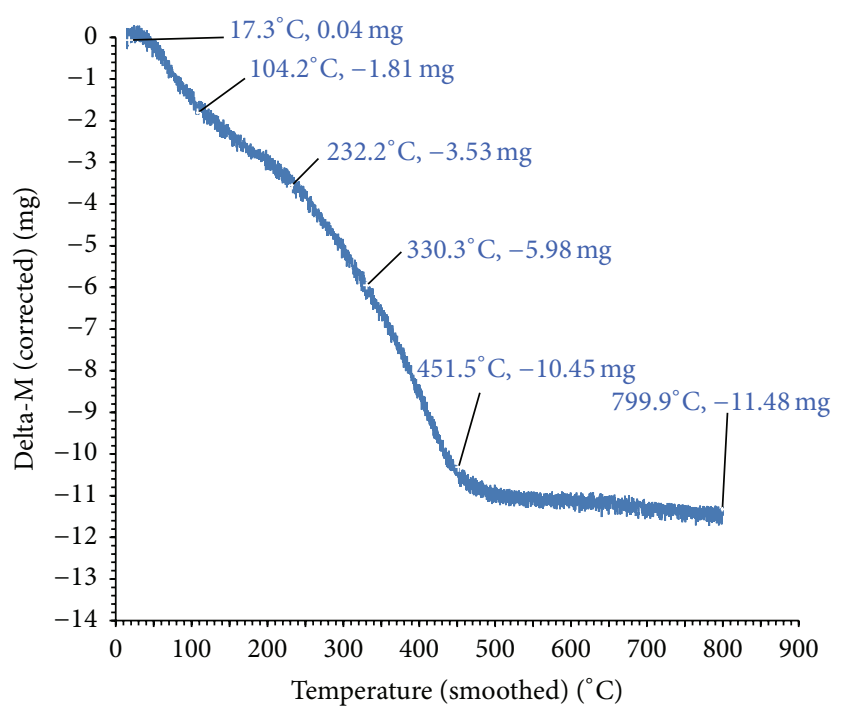

Figure 2: TGA curve of $\mathrm{Fe}_{3} \mathrm{O}_{4}$-Polymer.

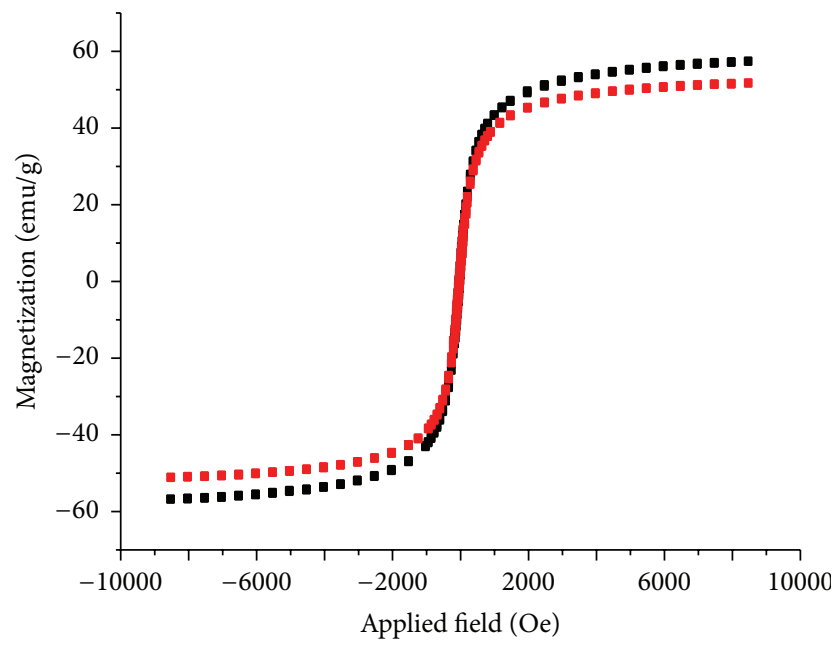

- $\mathrm{Fe}_{3} \mathrm{O}_{4}$

- $\mathrm{Fe}_{3} \mathrm{O}_{4}$-Polymer

Figure 3: Magnetic hysteresis curve of $\mathrm{Fe}_{3} \mathrm{O}_{4}$ and $\mathrm{Fe}_{3} \mathrm{O}_{4}$-Polymer.

From Figures 1 and 2, we can realize that the nanoparticles have core-shell structure.

Magnetic hysteresis curves of $\mathrm{Fe}_{3} \mathrm{O}_{4}$ and modified PEI $\mathrm{Fe}_{3} \mathrm{O}_{4}$ NPs at room temperature are shown in Figure 3.

The nanoparticles display saturation magnetization equal to 57.09 and 51.4 for $\mathrm{Fe}_{3} \mathrm{O}_{4}$ and modified PEI-Fe $\mathrm{O}_{3} \mathrm{O}$ emu/g. Saturation magnetization of FA-PEI-Sb-MNPs was lower than that of $\mathrm{Fe}_{3} \mathrm{O}_{4}$ that could be attributed to the modified polymer on the surface of nanoparticles. Paramagnetic behavior can use for carrier targeting and make them suitable for use in the pharmaceutical field.

The SEM micrograph of $\mathrm{Fe}_{3} \mathrm{O}_{4}$-PEI nanoparticles is shown in Figure 4. The SEM images exhibit that the mean particle size is $17 \mathrm{~nm}$. These images show that magnetic nanoparticles have spherical structure and enough monodispersity. 

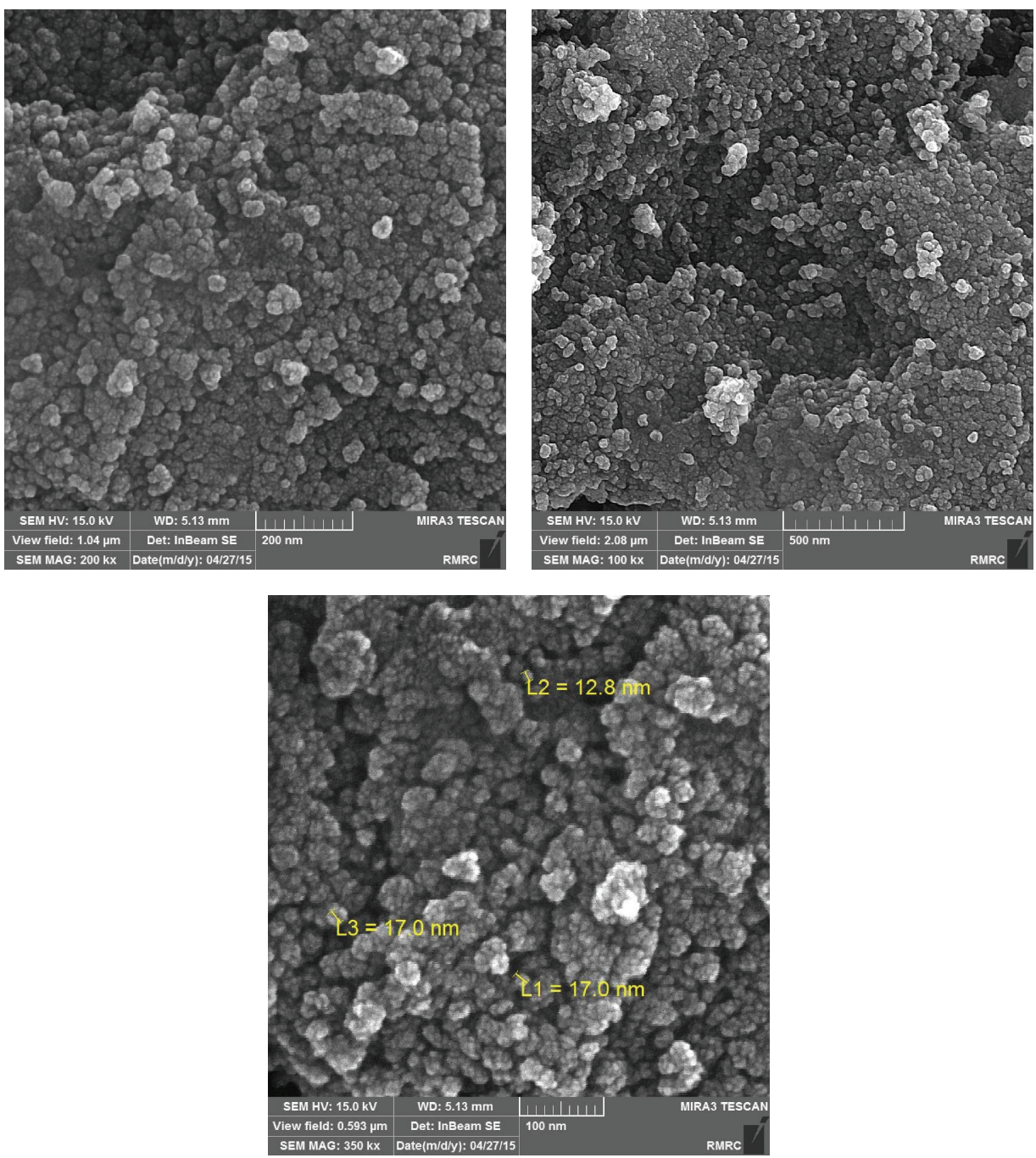

FIGURE 4: The SEM micrographs of FA-PEI-Sb-MNP nanoparticles and hydrodynamic size of them.

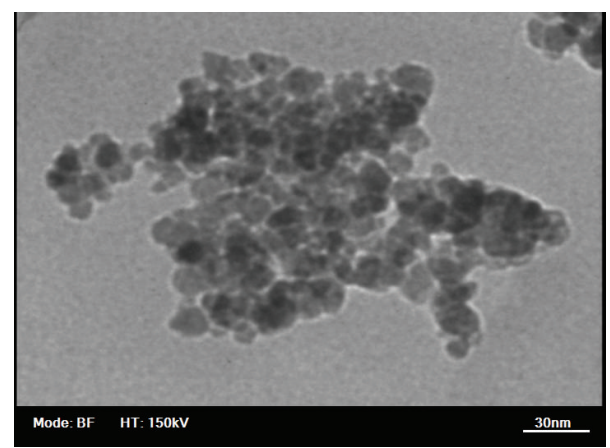

FIgure 5: Transmission electron microscopy images of FA-PEI-SbMNP.

TEM (transmission electron microscopy) images of nanoparticles are shown in Figure 5.

The FTIR spectra of PEI, PEI-Sb, and FA-PEI-Sb are shown in Figure 6(a) and the FTIR spectrum of polymer coated- $\mathrm{Fe}_{3} \mathrm{O}_{4}$ is shown in Figure 6(b).
The band at 1609.01 can be ascribed to amide bond and the bands at 2916.83 and 2849.10 could be related to the stretching vibration of $\mathrm{C}-\mathrm{H}$ bonds of the alkyl chain. The peak at 1705.49 shows the presence of carboxyl group (Figure 6(a), FTIR spectrum of PEI-Sb-FA). The major peaks for FA-SbPEI-Fe ${ }_{3} \mathrm{O}_{4}$ NPs can be determined as follows: $3353.65(\mathrm{~N}-\mathrm{H}$ stretchering vibration), 2923.04, and 2837.53 (C-H stretching), 1026.56 ( $\mathrm{C}-\mathrm{N}$ vibration), and 1661.91 ( $\mathrm{C}=\mathrm{O}$ amide) (Figure 6(a), FTIR spectrum of PEI-Sb).

The calibration curve was used to calculate the drug loading in nanoparticles (Figure 7). The drug loading content of obtained magnetic nanoparticles showed a value equal 28.2\%. The presence of Sb moiety conjugated with PEI- $\mathrm{NH}_{2}$ produce amphiphilic character for the polymer which can control drug loading and drug release due to the $\mathrm{pH}$ sensitivity of the polymer as well as high affinity to cell penetration due to the positive charge of the carrier surface interaction with.

The release study of curcumin showed that release of curcumin in acidic medium was more sensitive than neutral 


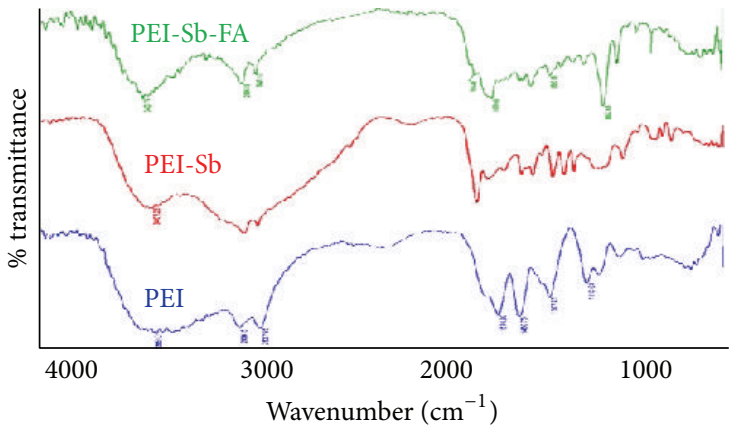

(a)

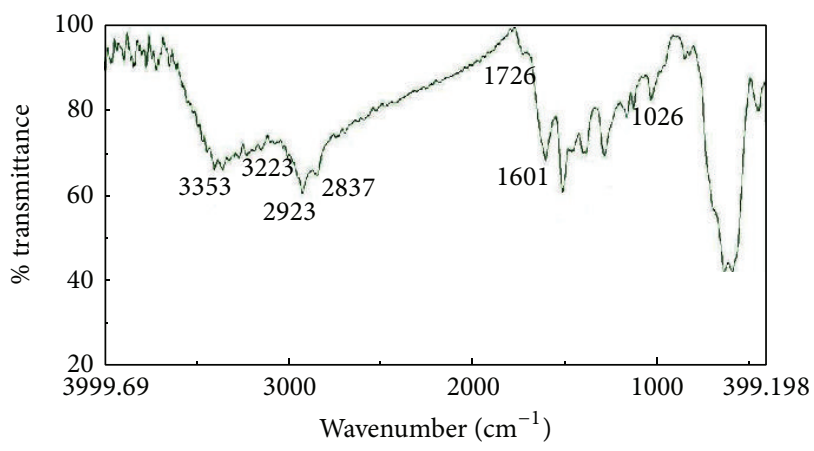

(b)

FIgURE 6: FTIR spectra of PEI with different ligands (a) and core-shell $\mathrm{Fe}_{3} \mathrm{O}_{4}$-modified PEI nanoparticles (b).

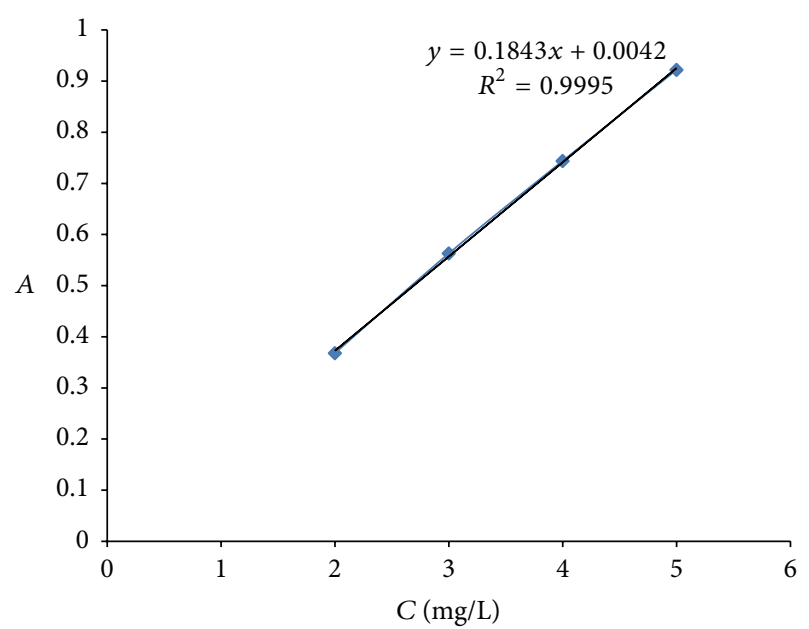

FIgURE 7: Curcumin loading calibration curve.

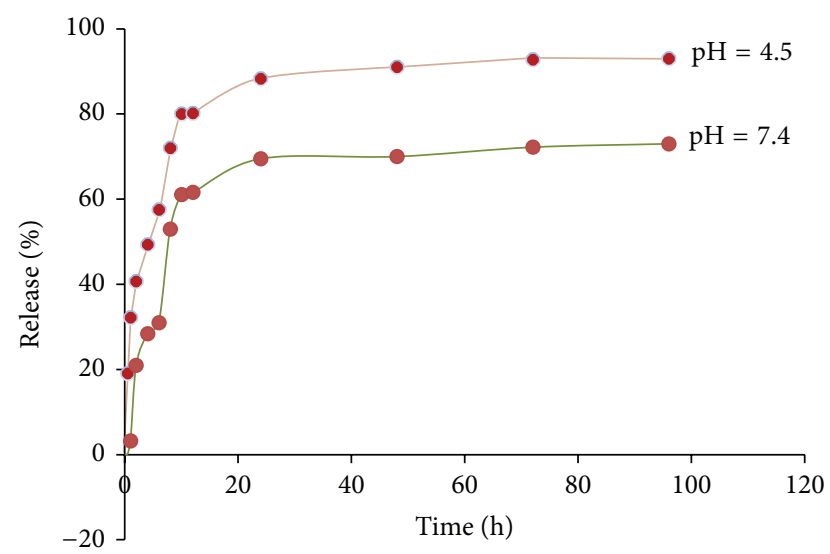

FIGURE 8: Evaluation of curcumin release from FA-PEI-Sb-MNPs.

medium and that is in accordance with cancer cell conditions (Figure 8).

\section{Conclusion}

Briefly, we synthesized a modified PEI coated magnetic in which PEI was modified by sebacoyl chloride and targeted by folic acid. Particles diameter can be controlled by the relative amount of polymer. Nanoparticles were characterized by FTIR, XRD, VSM, SEM, and TGA. The results adapted each other. Curcumin was loaded into nanoparticles and release behavior was investigated.

\section{Competing Interests}

The authors declare that they have no competing interests.

\section{Acknowledgments}

The authors would like to thank Assistant Farzaaneh Zaaeri (Tehran University of Medical Sciences, Faculty of Pharmacy, Department of Pharmaceutics) for editorial assistance and laboratory suggestions.

\section{References}

[1] G. Orive, R. M. Hernández, A. R. Gascón, A. Domínguez-Gil, and J. L. Pedraz, "Drug delivery in biotechnology: present and future," Current Opinion in Biotechnology, vol. 14, no. 6, pp. 659664, 2003.

[2] W. H. de Jong and P. J. A. Borm, "Drug delivery and nanoparticles: applications and hazards," International Journal of Nanomedicine, vol. 3, no. 2, pp. 133-149, 2008.

[3] M. Namdeo, S. Saxena, R. Tankhiwale, M. Bajpai, Y. M. Mohan, and S. K. Bajpai, "Magnetic nanoparticles for drug delivery applications," Journal of Nanoscience and Nanotechnology, vol. 8, no. 7, pp. 3247-3271, 2008.

[4] K. J. Widder, A. E. Senyei, and D. G. Scarpelli, "Magnetic microspheres: a model system for site specific drug delivery in vivo," Proceedings of the Society for Experimental Biology and Medicine, vol. 158, no. 2, pp. 141-146, 1978.

[5] M. M. Yallapu, S. F. Othman, E. T. Curtis, B. K. Gupta, M. Jaggi, and S. C. Chauhan, "Multi-functional magnetic nanoparticles for magnetic resonance imaging and cancer therapy," Biomaterials, vol. 32, no. 7, pp. 1890-1905, 2011. 
[6] S. C. McBain, H. H. P. Yiu, and J. Dobson, "Magnetic nanoparticles for gene and drug delivery," International Journal of Nanomedicine, vol. 3, no. 2, pp. 169-180, 2008.

[7] W. T. Godbey, K. K. Wu, and A. G. Mikos, "Poly(ethylenimine) and its role in gene delivery," Journal of Controlled Release, vol. 60, no. 2-3, pp. 149-160, 1999.

[8] B. B. Aggarwal and K. B. Harikumar, "Potential therapeutic effects of curcumin, the anti-inflammatory agent, against neurodegenerative, cardiovascular, pulmonary, metabolic, autoimmune and neoplastic diseases," The International Journal of Biochemistry \& Cell Biology, vol. 41, no. 1, pp. 40-59, 2009.

[9] E. Kedar, O. Palgi, G. Golod, I. Babai, and Y. Barenholz, "Delivery of cytokines by liposomes. III. Liposome-encapsulated GMCSF and TNF- $\alpha$ show improved pharmacokinetics and biological activity and reduced toxicity in mice," Journal of Immunotherapy, vol. 20, no. 3, pp. 180-193, 1997.

[10] L. Bromberg, E. Fasoli, M. Alvarez, T. Alan Hatton, and G. L. Barletta, "Biguanide-, imine-, and guanidine-based networks as catalysts for transesterification of vegetable oil," Reactive \& Functional Polymers, vol. 70, no. 7, pp. 433-441, 2010.

[11] European Brewery Convention, Analysis Committee: AnalysisEBC, Fachverlag Hans Carl, Nuremberg, Germany, 7th edition, 2008.

[12] H. S. Yoo and T. G. Park, "Folate-receptor-targeted delivery of doxorubicin nano-aggregates stabilized by doxorubicin-PEGfolate conjugate," Journal of Controlled Release, vol. 100, no. 2, pp. 247-256, 2004.

[13] S. Balasubramanian, A. R. Girija, Y. Nagaoka et al., "Curcumin and 5-fluorouracil-loaded, folate- and transferrin-decorated polymeric magnetic nanoformulation: a synergistic cancer therapeutic approach, accelerated by magnetic hyperthermia," International Journal of Nanomedicine, vol. 9, no. 1, pp. 437-459, 2014.

[14] M.-Y. Hua, H.-W. Yang, C.-K. Chuang et al., "Magnetic-nanoparticle-modified paclitaxel for targeted therapy for prostate cancer," Biomaterials, vol. 31, no. 28, pp. 7355-7363, 2010.

[15] T. Nguyen, Z. Gryczynski, S. Raut et al., "Formulation and preliminary evaluation of GMO coated magnetic nanoparticles for potential cancer therapy," in Proceedings of the National Conference on Undergraduate Research (NCUR '11), pp. 1265-1272, March-April 2011.

[16] A. Mukerjee and J. K. Vishwantha, "Formulation, characterization and evaluation of curcumin-loaded PLGA nanospheres for cancer therapy," Anticancer Research, vol. 29, no. 10, pp. 38673876, 2009. 

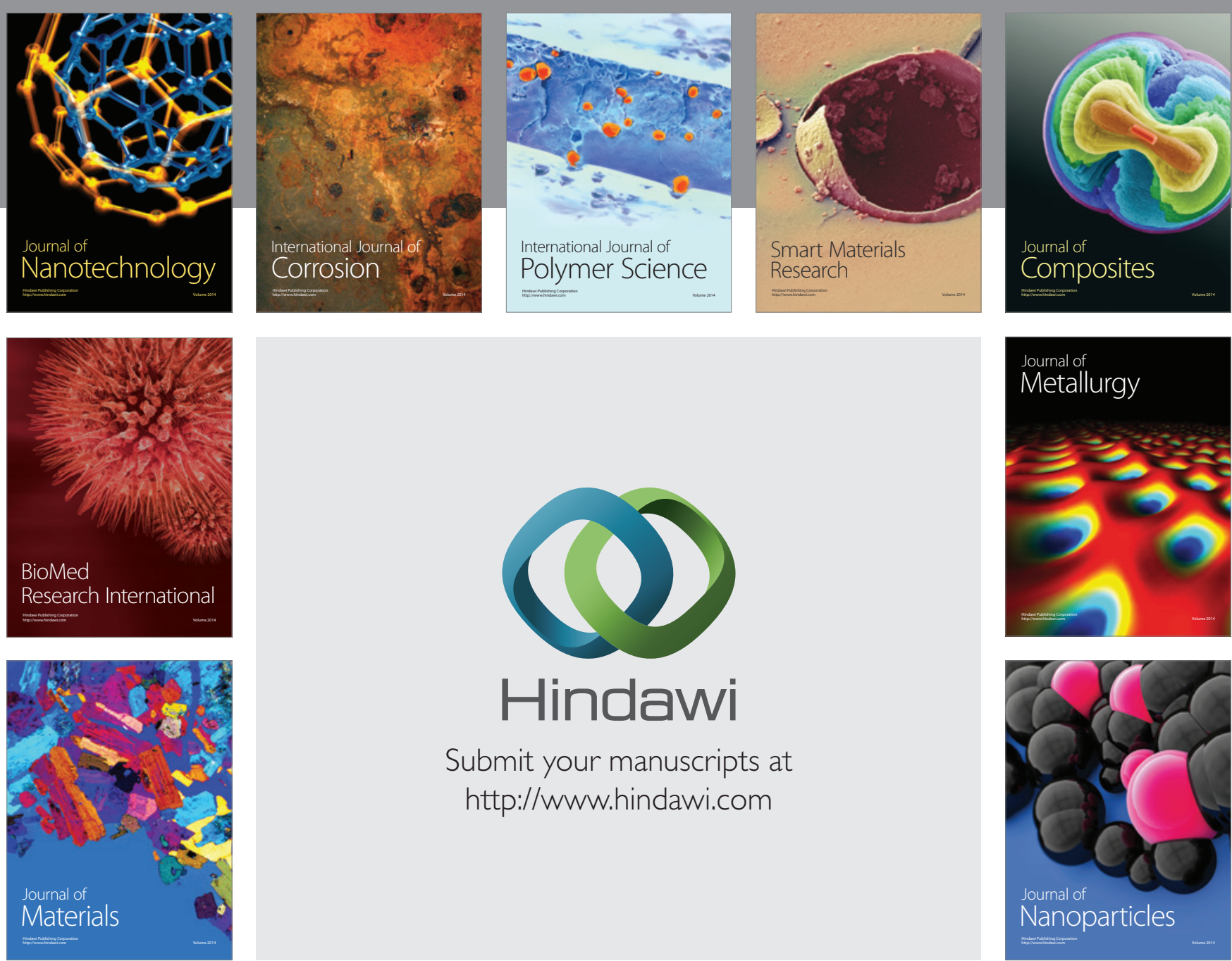

\section{Hindawi}

Submit your manuscripts at

http://www.hindawi.com

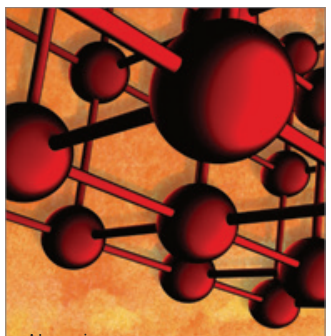

Materials Science and Engineering
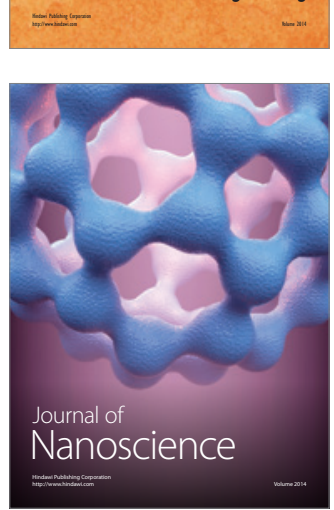
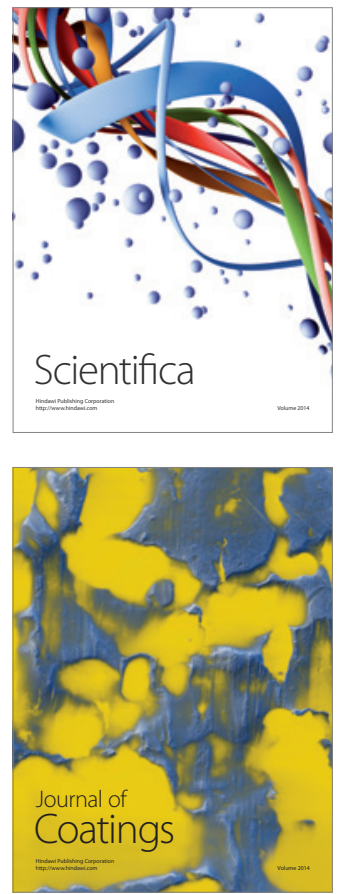
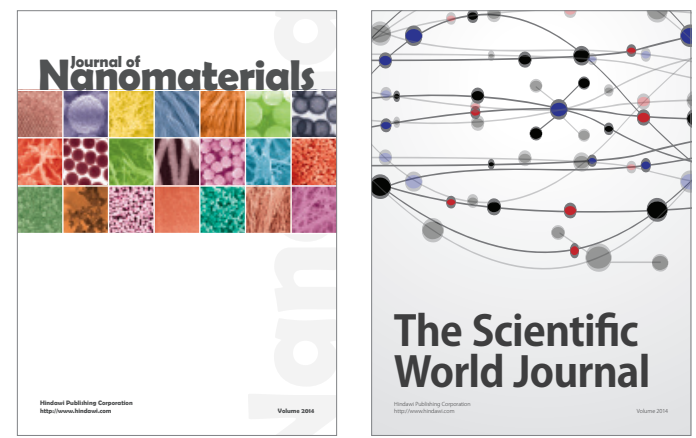

The Scientific World Journal
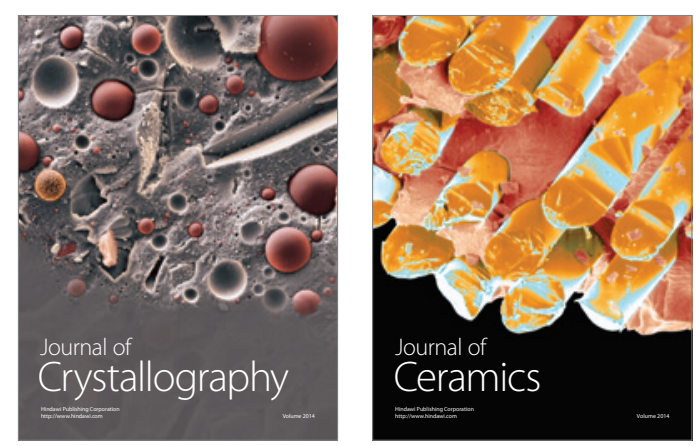
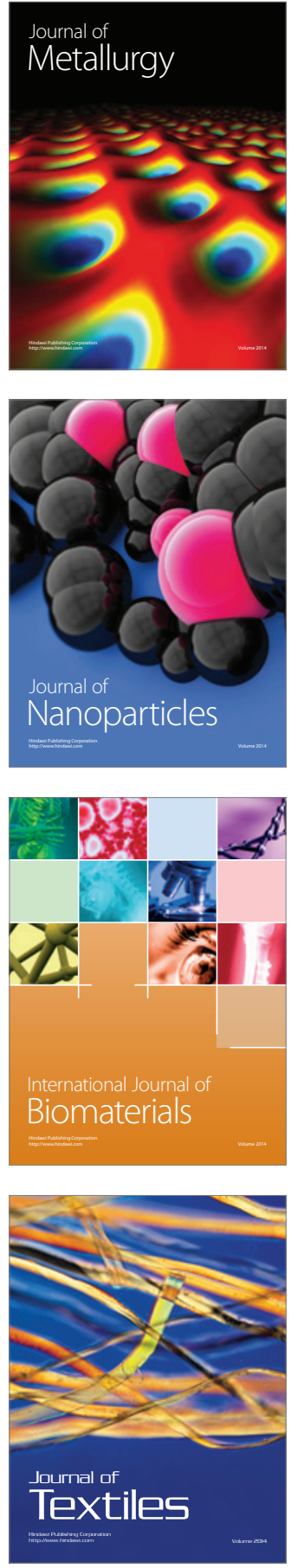